\title{
Del edificio al paisaje, una panorámica metodológica de la Arqueología de la Arquitectura en el banco de pruebas de Vitoria-Gasteiz (País Vasco)
}

\section{From the building to the landscape: a panoramic methodological overview through the Archaeology of Architecture in the case of the Vitoria-Gasteiz test bench (Basque Country)}

\author{
Amaia Mesanza-Moraza1 ${ }^{1}$ Ismael García-Gómez², Agustín Azkarate ${ }^{3}$ \\ Grupo de Investigación en Patrimonio Construido (GPAC) de la Universidad del País Vasco (UPV/EHU)
}

\section{RESUMEN}

El presente artículo está pensado para ofrecer una panorámica general de diversas metodologías que, respetando la perspectiva estratigráfica inherente a la Arqueología de la Arquitectura, se han ensayado en las últimas dos décadas con el fin de ampliar el horizonte de aplicabilidad de la disciplina, desde el ámbito habitual de trabajo que es el edificio singular, para llegar al paisaje antropizado. Prácticamente todas las experiencias de las que se habla han sido desarrolladas por el Grupo de Investigación en Patrimonio Construido de la UPV/EHU en el ámbito territorial del municipio de Vitoria-Gasteiz.

Palabras clave: metodología; lectura estratigráfica de alzados; análisis clúster; paisajes históricos.

\begin{abstract}
The goal of this paper is to provide a general overview of some methodologies that have been tried out over the last two decades trying to increase the applicability of the Archaeology of Architecture. We will review the usual field of work-the singular building-to reach to the anthropized landscape. Practically all the experiences mentioned have been developed by the Research Group on Built Heritage of the UPV/EHU in the territorial area of the municipality of Vitoria-Gasteiz.
\end{abstract}

Key words: methodology; reading elevation; cluster analysis; historical landscapes.

Recibido: 29-06-2020. Aceptado: 24-08-2020. Publicado online: 10-12-2020

Cómo citar este artículo / Citation

Mesanza-Moraza, A., García-Gómez, I. y Azkarate, A. 2020: "Del edificio al paisaje, u na panorámica m etodológica de la A rqueología de la Arquitectura en el banco de pruebas de Vitoria-Gasteiz (País Vasco)", Arqueología de la Arquitectura, 17: e102. https://doi.org/10.3989/arq. arqt. 2020.010

Copyright: (c) CSIC, 2020. ( ) UPV/EHU Press, 2020. Este es un artículo de acceso abierto distribuido bajo los términos de la licencia de uso y distribución Creative Commons Reconocimiento 4.0 Internacional (CC BY 4.0).

amaia.mesanza@ehu.eus / ORCID iD: https://orcid.org/0000-0001-5162-8955

ismael.garcia@ehu.eus / ORCID iD: https://orcid.org/0000-0002-1464-8268

agustin.azkarate@gmail.com, agustin.azcarate@ehu.eus / ORCID iD: https://orcid.org/0000-0002-0240-4960 


\section{INTRODUCCIÓN}

Han pasado ya prácticamente dos décadas desde la celebración del Seminario Internacional de Arqueología de la Arquitectura en Vitoria-Gasteiz, dos décadas durante las que la disciplina no ha dejado de crecer y transformarse para convertirse en lo que es hoy, una especialidad plenamente integrada y reconocida en el amplio campo de las ciencias arqueológicas. Muchas cosas han cambiado desde entonces, otras sin embargo perviven prácticamente intactas ya desde el citado Seminario que podríamos considerar como el "acta fundacional" de la Arqueología de la Arquitectura española, aunque en realidad ya hacía unos cuantos años que venían dándose distintas experiencias por toda la península. Quisiéramos que dos de esas pervivencias sirvieran como punto de partida para el presente artículo.

Hablamos en realidad de dos ideas ya recogidas en aquel documento que bajo el título "Arqueología de la Arquitectura: definición disciplinar y nuevas perspectivas" sirvió como editorial del primer número de la revista en que ahora mismo usted está leyendo estas líneas (Azkarate et al. 2002: 8). La primera de esas ideas reza del siguiente modo:

Si algo caracteriza a la arqueología de la arquitectura, desde el punto de vista instrumental, es su carácter estratigráfico. Aquí nos encontramos, sin embargo, con un grave problema, si tenemos en cuenta que la alfabetización estratigráfica de la arqueología española no es todavía completa. Urge, en consecuencia, la adopción plena de la estratigrafía como columna vertebral de la disciplina y, en este sentido, debe hacerse un esfuerzo de normalización en el uso consensuado de nuestro utillaje metodológico.

La segunda de esas ideas fue expresada del siguiente modo:

Esta afirmación [la del carácter estratigráfico de la Arqueología de la Arquitectura], no debe ser vista sin embargo de forma excluyente. Otros instrumentos de carácter tipológico, formal, estructural, arqueométrico o el recurso a las fuentes escritas son absolutamente imprescindibles para lograr un afianzamiento más sólido de la historia constructiva de los edificios históricos.

Pues bien, si hemos creído interesante comenzar estas líneas con esas dos referencias es porque pensamos que son definitorias de lo que la Arqueología de la Arquitectura sigue siendo en la actualidad, una disciplina que, sin perder esa referencia fundamental que es el análisis estratigráfico, sabe mostrarse flexible y abierta a otras aportaciones y perspectivas que contribuyan al estudio del fenómeno arquitectónico.

La panorámica que vamos a ensayar en el presente artículo va a ser, necesariamente, solo un esbozo. Afortunadamente, la Arqueología de la Arquitectura se ha diversificado y enriquecido tanto, que un abordaje global de todas sus ramificaciones exigiría cuando menos una obra monográfica, y nuestra intención aquí no es tanto buscar la exhaustividad como trazar un recorrido que sirva a todos aquellos investigadores o investigadoras latinoamericanas que estén interesados por esta especialidad para hacerse una idea global de dónde venimos, dónde estamos y hacia dónde creemos estar yendo aquellos que ya llevamos un tiempo practicándola en Europa.

Bajo una apariencia de retrospectiva, el discurso expositivo que vamos a adoptar en los siguientes epígrafes pretende hacer un sucinto, pero completo repaso, no tanto de todas las técnicas que hoy día se emplean en Arqueología de la Arquitectura, como de aquellos procedimientos metodológicos clave utilizados a la hora de abordar, no solo el estudio de los edificios históricos sino también el de los paisajes históricos. Asimismo, con objeto de trasladar al lector, no una descripción más o menos aproximada de cada uno de ellos, sino una visión más cercana y directa desde la experiencia de trabajo, hemos preferido adoptar una perspectiva en primera persona desde la óptica de algunos de los proyectos que hemos realizado a lo largo de estos años en el Grupo de Investigación en Patrimonio Construido (UPV/ EHU), centrándonos especialmente en aquellas investigaciones realizadas en el ámbito de Vitoria (Fig. 1).

En definitiva, hemos articulado el presente trabajo en cuatro partes. Una primera en la que, más que nada para recalcar su importancia dentro de la disciplina, haremos un brevísimo recorrido por los orígenes de la arqueología estratigráfica hasta llegar a la Arqueología de la Arquitectura. Una segunda parte, en la que profundizaremos en la "lectura estratigráfica de alzados", que es la más conocida y empleada de todas las técnicas propias de nuestra especialidad. En tercer lugar, abriremos la panorámica, para hablar de otras técnicas estratigráficas que, partiendo de un análisis de carácter tipológico, permiten abordar realidades construidas que por su escala son sensiblemente más complejas de las asumibles con una lectura estratigráfica al uso. En un cuarto bloque, y partiendo de las bases puestas en el anterior apartado, trataremos finalmente algunas técnicas que nos permiten dar el salto de la lectura estratigráfica del edificio a la del paisaje construido. 


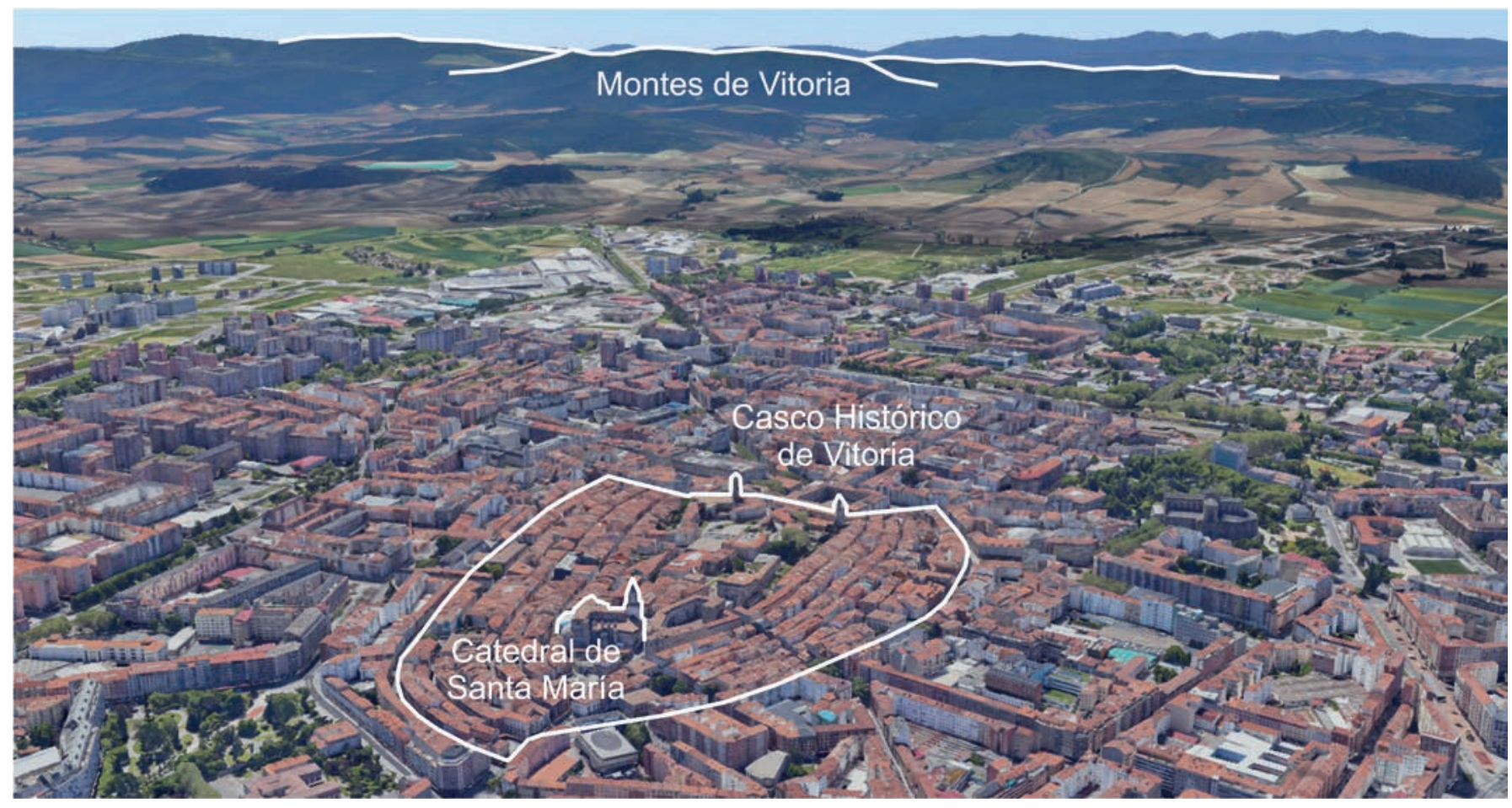

Figura 1. Tres proyectos y tres posibles escalas de análisis estratigráfico: edificio individual, centro histórico y paisaje antropizado. Fuente: elaboración propia sobre modelo Google Earth.

\section{ORIGEN Y DIFUSIÓN DEL ANÁLISIS ESTRATIGRÁFICO APLICADO A EDIFICIOS}

Si bien en sus orígenes la primera arqueología nació principalmente interesada en el rescate y estudio de los artefactos depositados en el subsuelo, entrado el siglo XX ese interés fue desplazándose hacia el conocimiento del contexto estratigráfico en el que aquellos aparecían. Esto sucedió en buena medida porque los investigadores fueron dándose cuenta de que para proponer la datación de esos objetos arqueológicos que tanto les preocupaban, además del estudio tipológico, el conocimiento de la secuencia en que se habían depositado los estratos que los contenían, aportaba información preciosa de carácter cronológico que servía para mejorar las dataciones.

El primer jalón de la arqueología estratigráfica hay que ubicarlo en el Reino Unido. Nombres importantes en su primer desarrollo son los de M. Wheeler y K. Kenyon, si bien aquellos que verdaderamente la consolidaron fueron sus herederos. Investigadores como M. Biddle y $\mathrm{Ph}$. Barker, pero sobre todo E. C. Harris, que con su propuesta de los principios de estratigrafía arqueológica y la invención del diagrama estratigráfico (también conocido como Matrix Harris), puso las bases del paradigma de registro arqueológico vigente aún hoy día. Corren por entonces los años setenta (Harris 1979).

Estas innovaciones gestadas en ámbito británico rápidamente empezaron a difundirse por toda Europa, siendo sin duda la arqueología italiana la que, de un modo más temprano y decidido adoptó las técnicas estratigráficas, destacando como uno de sus mayores defensores A. Carandini. No obstante, los precursores del salto de la arqueología estratigráfica del subsuelo al edificio fueron principalmente T. Mannoni, R. Parenti, R. Francovich o F. Doglioni, sin olvidar por supuesto a G. P. Brogiolo (1988) que fue quien escribió el primer manual de la disciplina bajo el título: Archeología dell'edilizia storica.

En España el interés por la arqueología estratigráfica de los edificios también había comenzado en los 80 , pero podríamos decir que de una forma algo más tímida. Nombres a destacar como pioneros en la Península Ibérica cabe mencionar a L. Caballero (Azkarate 2001), y como no también al equipo catalán del Servei del Patrimoni Arquitectònic (Utrero Agudo 2010: 18). En ámbito vasco, será A. Azkarate quien, en un fluido intercambio de pareceres y procedimientos con el equipo de L. Caballero, vaya incorporando la Arqueología de la Arquitectura a su bagaje metodológico. Fueron estos, junto con J. A. Quirós, los principales impulsores del Seminario Internacional de 
Arqueología de la Arquitectura celebrado en 2002 en Vitoria-Gasteiz, encuentro del que surgirá finalmente la revista científica Arqueología de la Arquitectura, una publicación claramente inspirada en su antecesora italiana.

\section{LA LECTURA ESTRATIGRÁFICA DE ALZADOS}

Desde que G. P. Brogiolo lo definiera en esa obra titulada Archeología dell'edilizia storica a la que ya hemos aludido, el procedimiento técnico más habitualmente empleado para determinar cómo se articula la estratificación de un edificio viene denominándose "lectura estratigráfica de alzados". Este procedimiento, siendo en extremo sintético, podríamos decir que consiste en determinar cuál es la estratificación de un inmueble, partiendo principalmente de una exploración directa de la materialidad del mismo. De esa estratificación identificada visualmente, o mejor, de las relaciones de antero-posterioridad entre estratos, será de la que a posteriori se deducirá el relato de la evolución constructiva del inmueble (Caballero Zoreda 1995: 37).

\subsection{Identificación de estratos}

El trabajo del arqueólogo o la arqueóloga de la arquitectura en la primera fase de los trabajos consiste esencialmente como decimos en ponerse delante del edificio y hacer una exploración directa de sus muros. El objetivo es individualizar primero estratos y, después, relaciones estratigráficas (García-Gómez 2019).

Para visualizar los estratos, el investigador o investigadora aplica un doble criterio, un doble criterio tan interiorizado que a menudo se emplea de forma automática, es decir, prácticamente sin ser consciente de ello. Este doble criterio tendría por un lado lo que hemos llamado la "estrategia interfacial". Esta se fundamenta en la búsqueda de aquellos indicios que denotan por dónde va el contorno del estrato, o si se prefiere cuáles son las "líneas fronterizas" que lo definen externamente. Estos indicios a veces son muy evidentes, pero en la mayor parte de las ocasiones se encuentran parcialmente difuminados en los muros. Por otro lado, estaría la que hemos denominado "estrategia tipológica" que busca la individualización del estrato a partir de la identificación de los rasgos internos que caracterizan su sustancia o contenido, rasgos que pueden ser muy diversos; desde el tipo de material constructivo empleado, hasta el tipo de aparejo o la presencia de determinadas marcas de cantero.
En cualquier caso, cada vez que se tiene identificado un estrato, este recibirá un número que servirá para distinguirlo inequívocamente del resto, siendo asimismo su morfología (forma, extensión, posición, etc.) anotadas sobre aquel repertorio gráfico base que se esté empleando en el registro del inmueble.

El sistema de registro en una lectura estratigráfica de alzados está compuesto por dos elementos fundamentales. Por un lado estaría ese repertorio gráfico en el que están representados todos los paramentos del inmueble estudiado, un registro gráfico que no es imprescindible que esté confeccionado mediante técnicas de captura topográfica (según las circunstancias del proyecto puede considerarse suficiente la realización de croquis, o una captura fotográfica ordinaria), si bien consideramos que, si existe la posibilidad, un buen trabajo topográfico siempre es mejor por el gran valor añadido que aporta al análisis estratigráfico (Álvarez-González et al. 2003; García-Gómez et al. 2011; Martín Talaverano 2014). Por otro lado, a parte de lo gráfico, es imprescindible en el registro, un conjunto de fichas analíticas que recoja, ficha por ficha, el desglose analítico de todas las observaciones hechas en cada uno de los estratos identificados (complementariamente, suele emplearse un tercer elemento, un listado-resumen que concentra, en un único documento, las denominaciones de cada una de las unidades estratigráficas individualizadas).

\subsection{Del estrato a las relaciones estratigráficas y a la secuencia temporal}

Ahora bien, más allá de los estratos es preciso analizar las relaciones físicas que los unen, pues es gracias a estas relaciones que podemos deducir la secuencia temporal en que se han ido produciendo los hechos estratigráficos. Para llegar a esta deducción es preciso cotejar la relación física observable con las llamadas "leyes de estratificación arqueológica" (la ley de superposición, la ley de horizontalidad original, la ley de continuidad original y la ley de sucesión estratigráfica; Harris 1991: 51-58). De ese modo, podremos establecer en términos de "cronología relativa" qué lugar ocupa, dentro de la secuencia temporal de la construcción del edificio, el estrato que estemos analizando.

Cuando se tienen todas las relaciones estratigráficas claras, es el momento de confeccionar el Diagrama de Secuencia Estratigráfica del Edificio, conocido comúnmente 
como Matrix Harris, el cual recoge, gráficamente, y de forma sintetizada, todos los estratos existentes en el edificio, eso sí, conjuntamente con las correspondientes relaciones de antero-posterioridad que los asocian. En el citado diagrama, cada estrato viene representado por una cartela con un número, único e intransferible, que es con el que, en la primera fase de exploración del inmueble, ya se le habrá denominado o identificado (tanto en el registro alfanumérico como en el registro gráfico). De la cartela de cada estrato salen diversas líneas que son las que representan gráficamente esos vínculos que ese estrato tiene con aquellos otros con él confinantes. Convencionalmente, los estratos más modernos son siempre representados en la zona superior del esquema y los más antiguos sucesivamente en niveles inferiores.

\subsection{Contextualización histórico- arqueológica del objeto de estudio}

No obstante, si bien con la lectura de alzados obtenemos la columna vertebral clave para la comprensión cronológica del edificio, los límites temporales de las distintas etapas constructivas detectadas mediante el análisis estratigráfico permanecerán difusas si es que no se puede recurrir a otras técnicas de datación que nos permitan precisar esos límites temporales. Una buena definición de estos es fundamental sobre todo si se aspira a contextualizar históricamente la evolución del edificio. Para ello, en una fase de los trabajos de lectura que podríamos denominar de "postproducción", se suelen explorar otras vías informativas complementarias, vías que podemos resumir en cuatro fundamentales; texto inscrito en los propios muros, documentación escrita (bibliográfica o de archivo), tipología y/o métodos físico químicos. Todas ellas nos servirán para precisar la cronología de los distintos estratos individualizados. Finalmente, gracias a estas otras formas de datación, aquella secuencia evolutiva deducida directamente del análisis estratigráfico del edificio, habrá ganado lo suficiente en nitidez y definición cronológica como para que toda esa información que ha quedado depositada en sus muros nos permita hacer otro tipo de inferencias de carácter histórico, ayudándonos por ejemplo al estudio de las técnicas constructivas, al de los usos del espacio, al de los ciclos productivos o sencillamente al de la contextualización socio-económica del edificio dentro del marco urbano o territorial en el que este se enclava (García-Gómez 2019).

\section{MÉTODOS ESTRATO-TIPOLÓGICOS}

Ahora bien, en determinadas circunstancias resulta imposible realizar una lectura estratigráfica de alzados al uso como la que acabamos de explicar en el anterior apartado. Nos estamos refiriendo a aquellos casos en los que las interfaces y el contorno de los estratos son imposibles de distinguir. Una situación que puede darse por varias razones: bien porque la fábrica del edificio se encuentre recubierta por un revestimiento que enmascara, total o parcialmente, la estratificación del inmueble, bien porque el conjunto a analizar tiene unas dimensiones que superan con mucho las capacidades perceptivas del investigador que se pone delante del muro a explorar y diferenciar contextos. Con todo, incluso en estas situaciones aún existen formas de rastrear (podríamos decir, indirectamente) esa estratificación en apariencia imperceptible.

A continuación, vamos a exponer, de forma necesariamente breve, diversos desarrollos metodológicos que hemos elaborado con el fin de adaptar la aproximación estratigráfica a otras realidades construidas de mayores dimensiones. Todas ellas tienen su origen de uno u otro modo en el llamado "análisis configuracional" y en la "cronotipología relativa", ambos conceptos teorizados principalmente por T. Mannoni, si bien a pesar de su gran potencialidad son herramientas a las que, creemos, aún no se les ha sacado suficiente partido.

Como se verá, en nuestro discurso expositivo iremos pasando de realidades de estudio menos extensas a otras más extensas, aunque no es nuestra intención con ello inducir a la confusión de que a mayor tamaño del objeto de estudio corresponde una metodología cada vez más compleja. En realidad, habría que hablar de una misma herramienta de trabajo ajustada en cada momento según el contexto de aplicación.

\subsection{Análisis configuracional y cronotipología relativa}

Existe como decimos un modo de inferir indirectamente la estratificación del edificio que, en esencia, consiste en realizar un análisis tipológico de aquellos rasgos formales visibles que se repiten en su arquitectura teniendo muy en cuenta la ubicación espacial de unos con respecto a otros; estamos refiriéndonos entre otros a los perfiles de capitel, a los perfiles de basa, a la sección de las nervaduras en una bóveda, a los tipos de arco o de dintel empleados en puertas y ventanas, etc. (GarcíaGómez et al. 2011). 
Este método de análisis también surgió en Italia y fue originalmente bautizado como "análisis configuracional" por aquellos que lo idearon (Mannoni 1998). $\mathrm{Su}$ operativa se basaba en una técnica o fundamento de registro conocido como "cronotipología relativa" (Ferrando Carona et al. 1989) que según la definición de Gabbrielli (1996: 17) consistía en

estudiar las variaciones del tipo para establecer si estas expresan diferencias cronológicas. En otros términos, las informaciones que emergen se basan en la individualización de las concordancias y discordancias existentes entre dos unidades de un elemento arquitectónico repetido en serie en un mismo edificio. La repetición en serie es una condición indispensable para la investigación.

Esta metodología fue aplicada con un éxito manifiesto en algunas investigaciones clásicas como la de la abadía de San Galgano (Gabbrielli 1998), o la del Palazzo Pubblico de Siena (Camporeale et al. 2001).

\subsection{Análisis clúster aplicado en la Catedral de Santa María de Vitoria}

Nuestra primera experiencia con la "cronotipología relativa" en el Grupo de Investigación en Patrimonio Construido (UPV/EHU) tuvo lugar a fines de la pasada centuria en la Catedral Santa María de Vitoria (Azkarate et al. 2001: 134-200; Azkarate 2010). No obstante, si bien en un principio nos ceñimos al modelo de "cronotipología relativa" definido en Italia, enseguida nos dimos cuenta de que, para que el método fuera verdaderamente aplicable en nuestro contexto, había que introducir algunos cambios, cambios que acabaron transformando tanto el concepto original que preferimos acuñar una nueva denominación para un método que al final calificamos como "análisis clúster". Algunas particularidades del nuevo diseño metodológico fueron la combinación de la estratigrafía con las técnicas cronotipológicas, y sobre todo la incorporación de un nuevo elemento conceptual, el clúster. No obstante, si tuviésemos que resaltar aquella aportación que consideramos más relevante, destacaríamos el hecho de que en nuestro caso el empleo de la "cronotipología relativa" seguía primando -como en la lectura estratigráfica clásica- la búsqueda e individualización de interfaces. Véase especialmente el cuarto punto de la siguiente secuencia operativa que en que se dividía nuestro procedimiento (Fig. 2):
1. Individualización de variables. Se registraron dos tipos de variables, por un lado, variables de carácter técnicoconstructivo (litología, aparejo, talla, marcas de cantero, etc.) y por otro, variables de carácter formal (tipos de puntilla en los arcos del triforio, tipos de capiteles, etc.).

2. Georreferenciación de variables seleccionadas. Se localizaron sobre la planimetría los puntos del edificio donde se manifestaban las distintas variables.

3. Individualización y mapeado de los clústeres de variables. Analizando el modo en que las variables dispersas por todo el templo tendían a asociarse en el espacio tridimensional de la catedral, fue posible individualizar distintos conjuntos de variables que tendían a agruparse y localizarse en determinadas partes del edificio. A cada uno de esos conjuntos o agrupaciones los considerábamos un clúster constructivo (por así decir, el equivalente de un estrato).

4. Análisis de las interfaces. Los clústeres constructivos representaban partes del edificio constructivamente homogéneas, pero su contorno quedaba indefinido. Para definir ese contorno se trabajaba sobre la representación planimétrica analizando la dispersión de las variables por los muros y según fuera esa dispersión se deducía donde estaban los límites interfaciales entre los clústeres.

5. Determinación de la secuencia relativa. Una vez definidos los contornos interfaciales, estos fueron empleados para estudiar y establecer las relaciones de anteroposterioridad que ligaban unos clústeres constructivos con otros. Gracias a ello se pudo establecer la secuencia cronológica relativa, el orden, en que se había ido produciendo la evolución arquitectónica del conjunto.

6. Determinación de la secuencia absoluta. El análisis de las relaciones estratigráficas existentes entre esas UUEE, en combinación con los estudios sobre la documentación escrita y otro tipo de dataciones absolutas, proporcionaron fechas concretas para determinadas acciones constructivas, lo que permitió la determinación de una secuencia cronológica absoluta y la contextualización histórica de la evolución constructiva de la catedral, siglo a siglo, año a año.

Como resultado de esta investigación en la catedral se detectaron un total de diez clústeres (Fig. 3) cada uno de ellos correspondiente a una de las siguientes etapas cronológicas: 1) preexistencias (anteriores a mediados del siglo XII);2) Alfonso VIII (1158-1214); 3) gótico A (ca. 1252-1295); 4) gótico $\mathrm{B}$ (ca. 1330-1400); 5) siglo XV; 6) siglo XVI; 7) siglo XVII; 8) siglo XVIII; 9) siglo XIX y 10) siglo XX. 


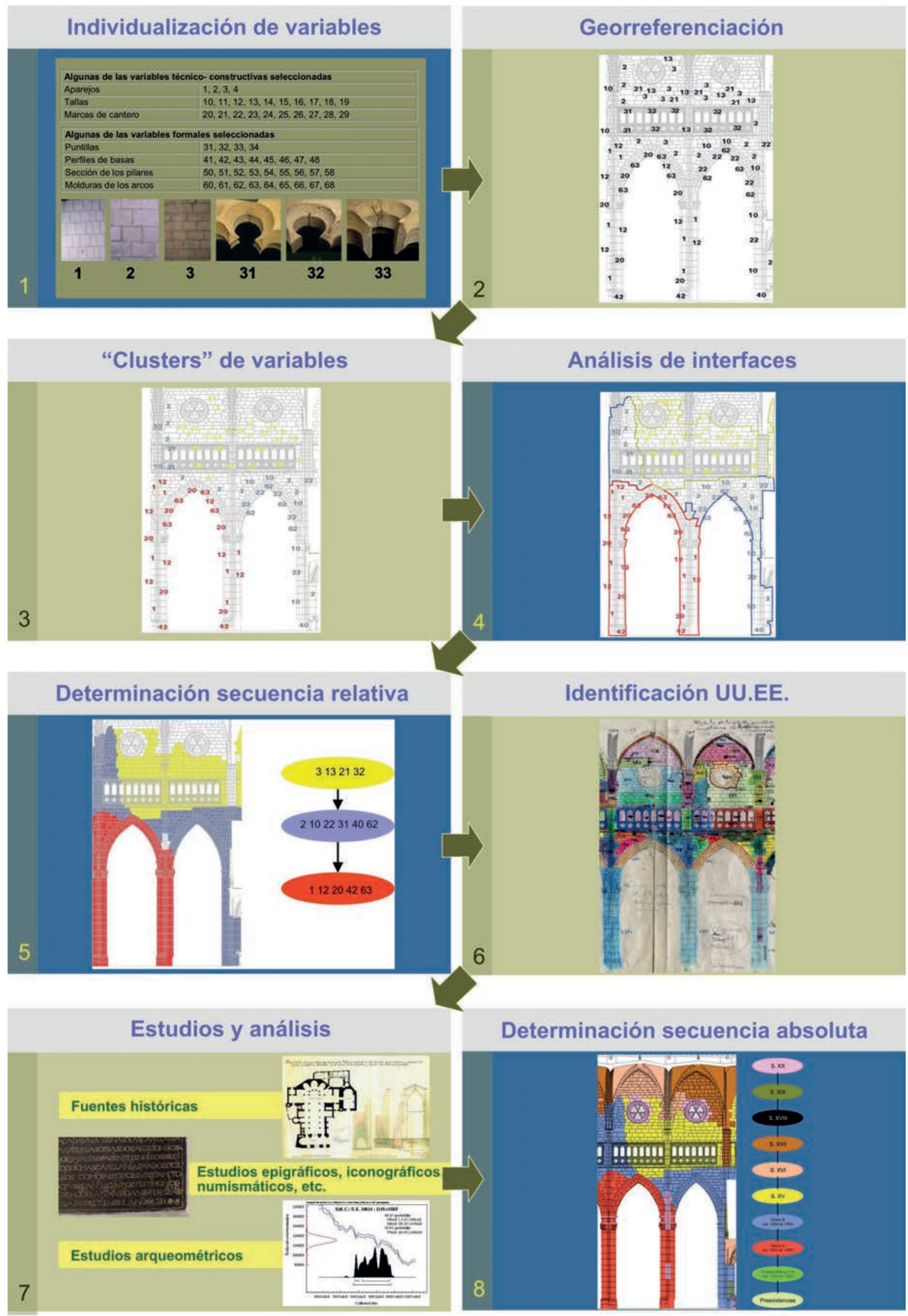

Figura 2. Secuencia operativa de la experiencia con la "cronotipología relativa" en la Catedral Santa María de Vitoria. Fuente: Azkarate $2010: 56$. 


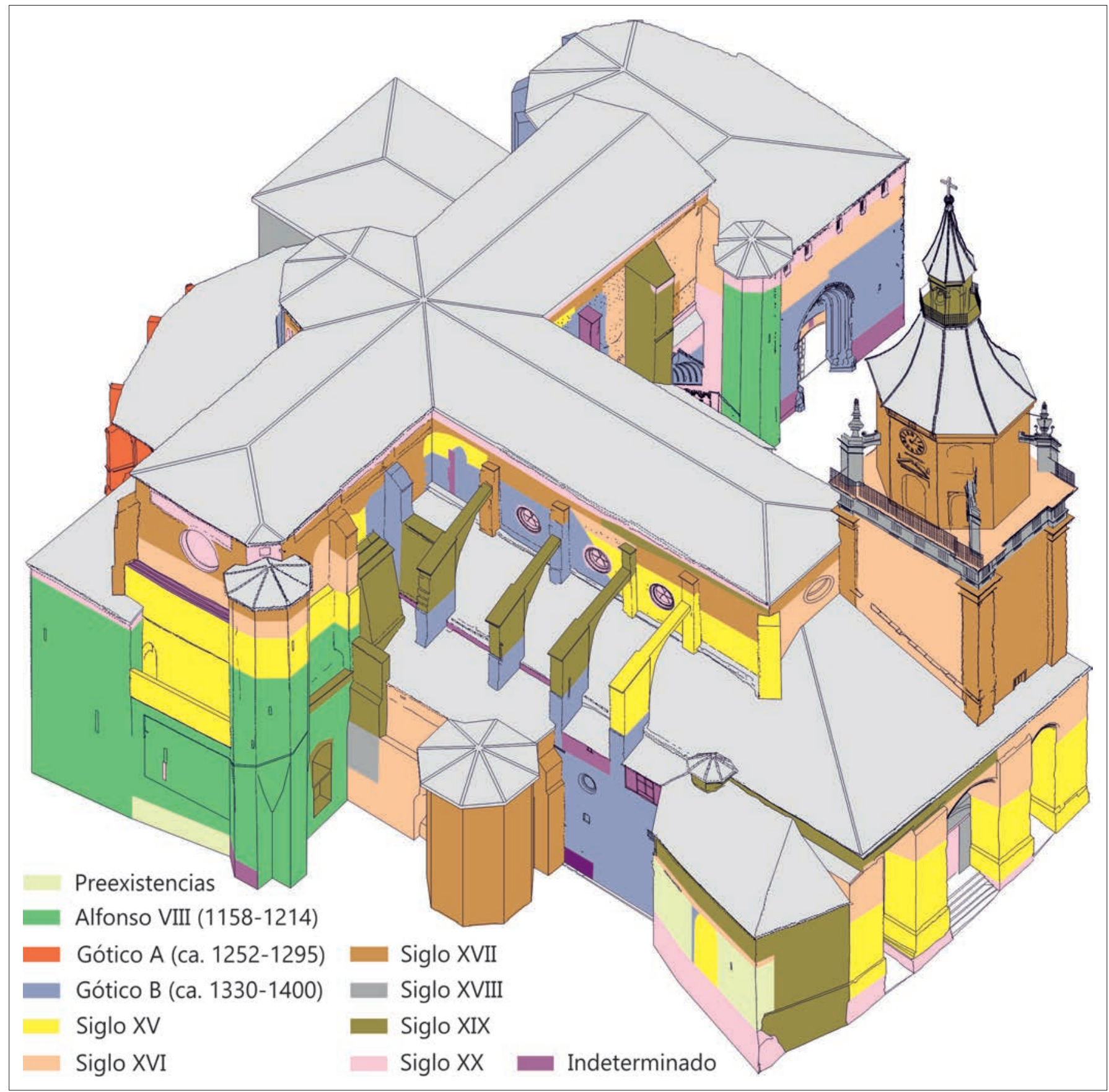

Figura 3. Fases constructivas individualizadas en la catedral Santa María por medio del "análisis clúster". Fuente: Azkarate et al. 2001: 134-200.

\section{ANÁLISIS ESTRATIGRÁFICO DEL PAISAJE ANTROPIZADO}

Insospechadamente, la metodología de "análisis clúster" desarrollada en la catedral no solo iba a permitirnos abordar el estudio de conjuntos histórico-arquitectónicos más complejos, sino que también iba a abrirnos un nuevo campo de investigación, el del paisaje antropizado. Las tesis doctorales que, desde nuestro grupo de investigación, defendieron L. Sánchez Zufiaurre (2007) sobre las iglesias prefeudales en Álava, y Alberto Plata (2008; Plata y Erkiaga 2018) sobre el valle salado de Añana nos proporcionaron claras muestras de que esto era posible. Por nuestra parte, decidimos que sería interesante intentar ponerlo en práctica en un casco urbano, y como es lógico, por cercanía (aunque también por su interés, como no) optamos por el de Vitoria-Gasteiz. 


\subsection{Análisis clúster aplicado a un paisaje histórico urbano, Vitoria- Gasteiz}

No éramos pioneros sin embargo en esto. Que tengamos conocimiento, las primeras experiencias de análisis estratigráfico y cronotipológico aplicadas a todo un conjunto urbano se produjeron en la Liguria de los años setenta y las llevó a cabo el Istituto di Storia della Cultura Materiale. Inspirados en aquellas tempranas experiencias del ISCUM y en las ya aludidas de Sánchez Zufiaurre y Plata pusimos marcha un nuevo proyecto de "análisis clúster" que se desarrolló en tres grandes fases a lo largo de prácticamente cinco años:

1. En una primera fase, que a pesar de ocuparnos dos años podríamos considerar preparatoria, el trabajo consistió en la estructuración y programación de un buen repositorio donde almacenar toda la información generada. No hablamos por supuesto de una simple base de datos sino de todo un Sistema de Información Geográfica que iba a ser clave, porque todos los datos introducidos en dicho repositorio debían estar referidos a algún punto o elemento concretamente localizado en el espacio. Asimismo, durante esta fase procedimos con un exhaustivo vaciado de informes de excavación arqueológica y de archivos, gracias al cual nos hicimos con prácticamente toda la cartografía histórica existente sobre Vitoria y tuvimos conocimiento de ciertos documentos de carácter municipal que al cabo del tiempo se demostrarían clave para obtener dataciones más precisas de ciertas realidades construidas.

2. En una segunda fase procedimos con la mayor parte del trabajo de campo, o dicho de otro modo, con la exploración directa de los inmuebles que forman parte del Casco Histórico de Vitoria, en busca de indicios reveladores de la estratificación de la realidad urbana. Hablamos siempre de hechos detectables sobre cota 0 , ya que no realizamos excavaciones específicas (aunque tuvimos muy en cuenta los datos recabados en el vaciado de informes de excavación arqueológica que habíamos hecho en la fase anterior). Por presentarlo de una forma más sistemática, podríamos hablar de seis grandes etapas de trabajo dentro de esta fase:

a) Prospección. Esta fue propiamente la fase de exploración y escrutinio de los inmuebles en la que se registraron todos los edificios y elementos constructivos que iban a ser analizados por variables. Se confeccionaron fichas detalladas de cada inmueble y se realizó asimismo la lectura estratigráfica de alzados (no en profundidad) de algunos conjuntos que presentaban particularidades relevantes desde el punto de vista cronológico.

b) Definición de variables. Con toda la información recabada en la fase anterior, en esta se seleccionaron aquellos elementos que, además de repetirse seriadamente en la mayoría de inmuebles, presentaban entre sí rasgos morfológicos netamente diferenciables y potencialmente indicadores de una cronología. El resultado de todo este proceso fue un listado de variables que se agrupaban en 10 familias; litología, tipo de aparejo, instrumento de labra, tipo de blasón, tipo de vano, tipo de balcón, tipo de mirador, tipo de medianil y modelo de histograma latericio.

c) Georreferenciación de variables. En esta fase se introdujeron en el SIG todos los elementos anteriormente catalogados con sus correspondientes variables asociadas en sus coordenadas " $x$ " e " $y$ " reales, es decir, se insertaron dentro de la planta del casco histórico de Vitoria que constituía la base de dicho Sistema de Información Geográfica.

d) Definición de variables diagnóstico. No todas las variables tienen la misma capacidad informativa, algunas se repiten tanto que resultan poco discriminantes o significativas, otras están tan escasamente representadas en la muestra que apenas permiten un trabajo de comparación. Con ayuda del Sistema de Información Geográfica descartamos todas aquellas $\mathrm{y}$ nos quedamos con un conjunto de rango intermedio, de tal forma que de un total de 10 familias de variables finalmente nos quedamos solo con tres: litología (7 variables), tipo de vano (20 variables) y el modelo de histograma latericio (4 variables).

e) Articulación de clústeres. Con base en la distribución de esas variables, sobre el plano del casco histórico de Vitoria, se determinó cuáles eran las agrupaciones más homogéneas y se definió su contorno o interfaz por medio del establecimiento de sus superficies de tendencia.

f) Establecimiento de la secuencia cronológica relativa. Atendiendo a la relación espacial entre los distintos clústeres definidos se estableció una secuencia de hechos urbanísticos que da cuenta del proceso de expansión del caserío del casco histórico de Vitoria.

Como resultado de esta investigación se detectaron un total de nueve clústeres (Fig. 4) que en la contextualización 

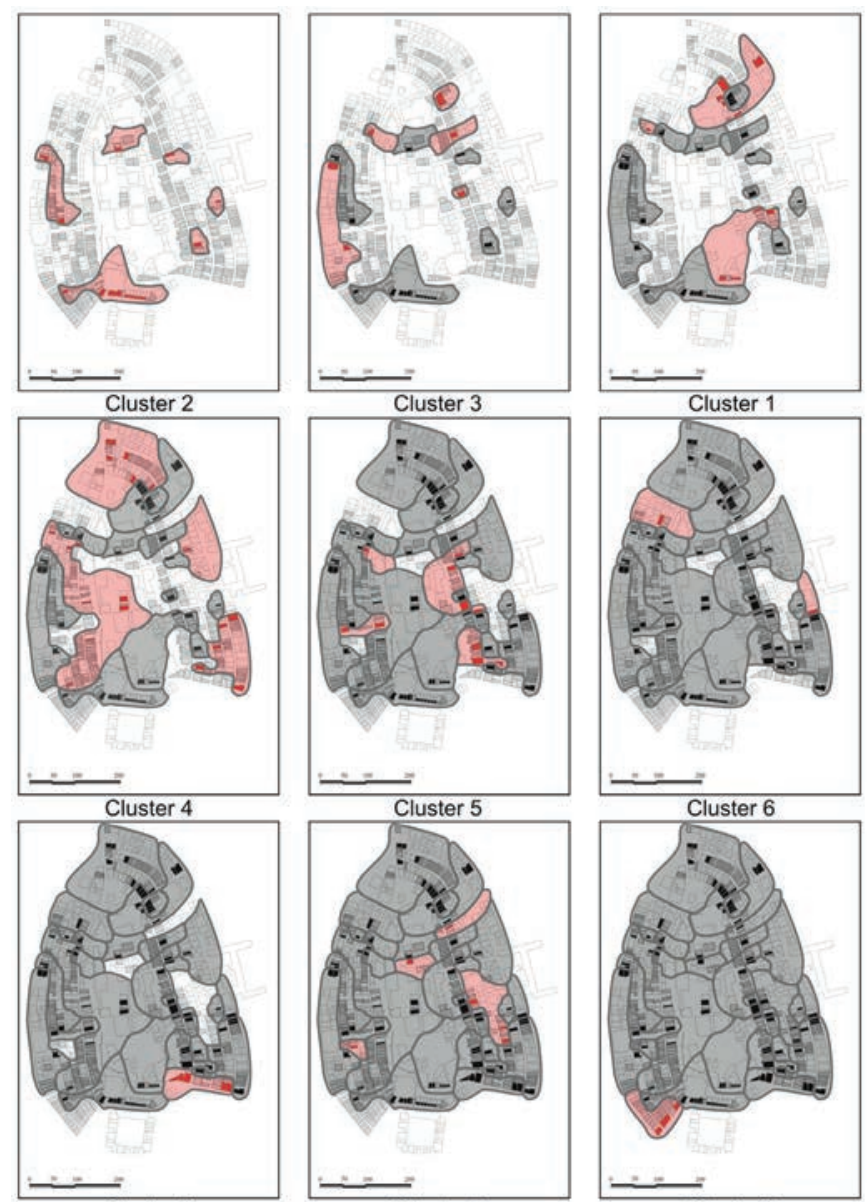

Cluster 8

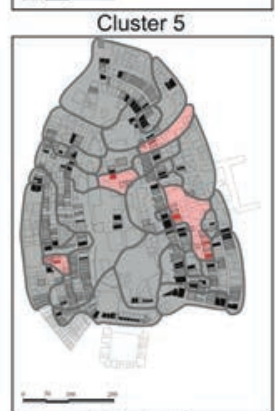

Cluster 7
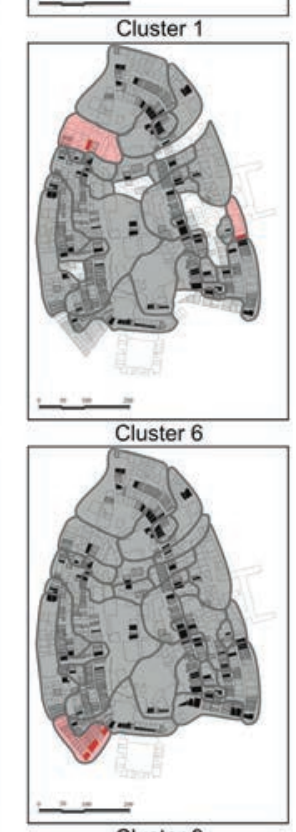

Cluster 9
Figura 4. Fases en la evolución del centro histórico de Vitoria-Gasteiz individualizadas mediante "análisis clúster". La numeración de los clústeres no tiene por qué coincidir con los de la secuencia relativa elaborada que debe leerse de arriba hacia abajo y de izquierda a derecha, correspondiendo el "clúster 2" a la primera fase. Fuente: Azkarate 2010.

arqueológica fueron interpretados y distribuidos en cinco etapas que denominamos del siguiente modo: 1) endogénesis (siglo XVII); 2) cambio de polaridad (fines del siglo XVII); 3) crecimiento (mediados del siglo XVIII); 4) drenaje (mediados del siglo XIX); 5) abandono (segunda mitad del siglo XIX) (Azkarate 2010).

Siempre dentro de esta segunda fase hay que decir que, en paralelo al procedimiento arriba indicado, también emprendimos otra vía metodológica de análisis del fenómeno urbano más en la clave del conocido space syntax de Hillier y Hanson (1989) (Fig. 5). En un principio, confiábamos en que este enfoque iba a ofrecernos múltiples posibilidades interpretativas, sin embargo, nos dimos cuenta de que, a pesar de ese interesante horizonte que se nos abría, este tipo de análisis no nos ayudaba a discernir la diacronía en la evolución del tejido urbano; lo cual, entendíamos (y entendemos) es una prioridad en Arqueología de la Arquitectura. Esta limitación observada en la metodología de la

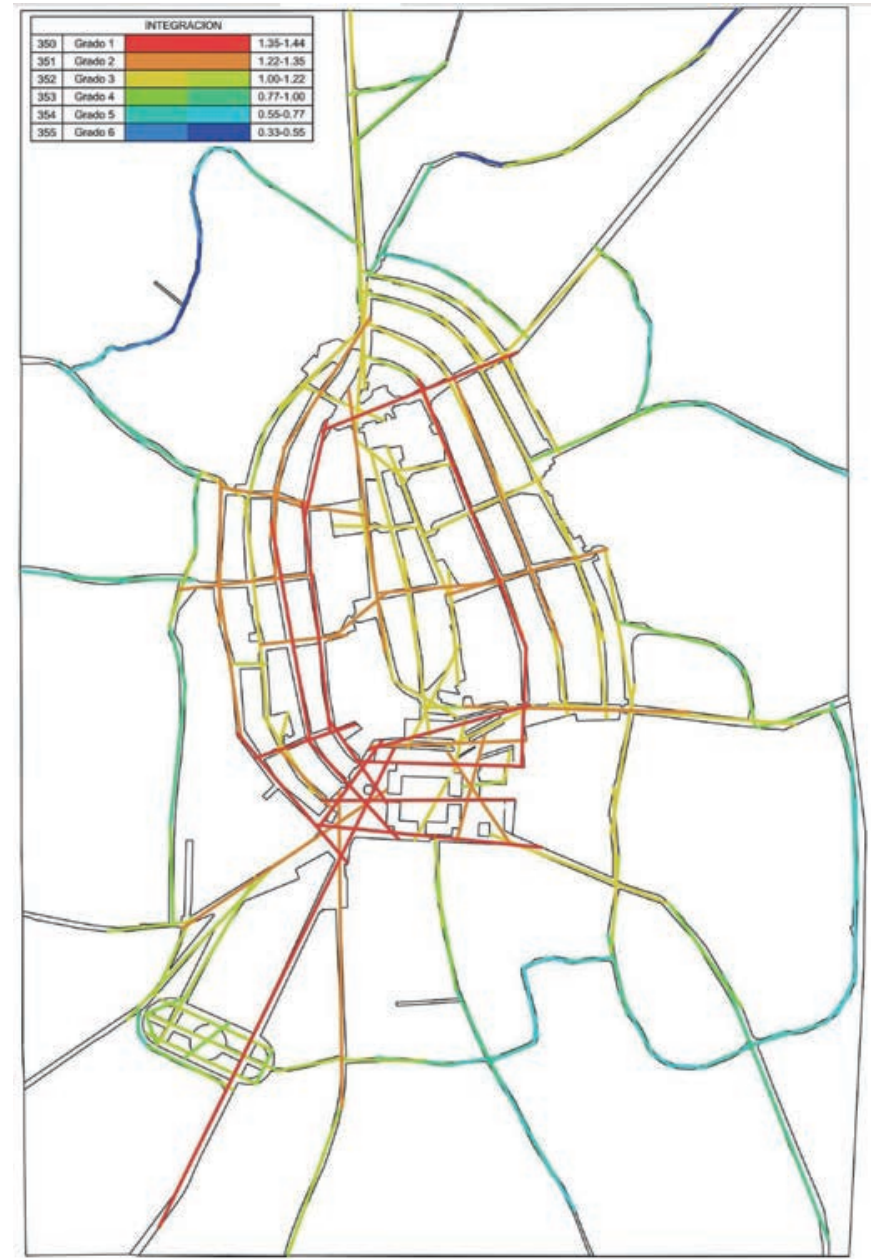

Figura 5. Análisis del grado de "integración global" del casco histórico de Vitoria-Gasteiz, una de las cuantificaciones más empleadas en los análisis sintácticos del espacio. Fuente: Azkarate 2010: 63, memoria inédita.

sintaxis espacial (y que también han percibido otros investigadores; Bermejo 2009: 57), acabó por convencernos de que teníamos que decantarnos por la vía del "análisis clúster" pues este sí que estaba específicamente diseñado para discernir etapas dentro de los fenómenos constructivos. Dicho de otro modo, una vez establecida (mediante "análisis clúster") cuál era la materialidad del tejido urbano en cada momento histórico, es cuando tendría sentido aplicar a cada uno de esos momentos por separado el análisis sincrónico de su sintaxis espacial.

\subsection{Análisis estratigráfico del trazado viario de Vitoria-Gasteiz}

En una tercera fase de aquella misma investigación sobre el casco histórico de Vitoria, optamos aún por una tercera estrategia para abordar, sin excavación, la estratigrafía de la ciudad antigua. Este trabajo, que se 
convirtió en tesis doctoral (García-Gómez 2017: 429481), partía de una sencilla reflexión que tiene que ver con que, cuando pensamos arqueológicamente en un tejido urbano, lo primero que suele venirnos en mente son los edificios que flanquean las calles y no tanto las calles en sí, es decir, no tanto su trazado. Sin embargo, es bastante obvio que, a la hora de estructurar un asentamiento, el papel del trazado viario es quizá más importante que el de las propias construcciones, pues es este el que permite el transporte y desplazamiento de un lugar a otro, un movimiento sin el que un núcleo habitado no podría ni subsistir, ni evolucionar. Decidimos por lo tanto fijar nuestro interés estratigráfico en esos trazados.

Advirtamos antes de seguir que cuando hablamos de analizar estratigráficamente los trazados viarios no nos estamos refiriendo a estudiar la estratigrafía de los distintos pavimentos que han ido sucediéndose en un mismo lugar, sino más bien al análisis de una estratigrafía de las ramificaciones de los trazados en sí con objeto de poder determinar distintos momentos en la evolución del tejido urbano. La metodología que empleamos en esta ocasión estaba inspirada en las reflexiones de R. Chevalier (1997), que, al analizar desde múltiples puntos de vista la red viaria del Imperio Romano, observó ciertas pautas en la configuración de esa retícula que podían servir como indicadores cronológicos. En esencia, se dio cuenta de que, si analizaba la morfología de las intersecciones entre caminos, según fuera la conjunción entre estos, era posible deducir una "cronología relativa", es decir, era posible deducir cuáles habían surgido de cuáles, o si se prefiere, cuáles eran anteriores y cuáles posteriores.

Nuestro trabajo partió por lo tanto de la hipótesis de que, esa suerte de principio de estratificación viaria que había descubierto Chevalier, podía funcionar no solo a escala regional, en vías de comunicación interurbanas sino también, dentro del propio tejido viario de un asentamiento. Los pasos que dimos hasta poder presentar una lectura estratigráfica de los trazados viarios de Vitoria fueron los siguientes:

1. Elaboración de la cartografía base. Para llevar a cabo este tipo de análisis tuvimos que hacernos con una buena cartografía de base, lo más precisa posible. Si es factible, las planimetrías de escala 1:5000 son una buena opción. Otra alternativa son las ortofotos de alta resolución. En este caso pudimos contar con las dos.
2. Individualización del "grafo maestro". Partiendo de aquella base cartográfica se elaboró otro plano de carácter más abstracto, o vectorial si se prefiere, que respetando la escala y geometría de los plano-base originales, recogía tan solo la línea de los trazados de calles y caminos. A este plano lo denominamos "grafo maestro" y representaba el esqueleto viario de la urbe, dejando a un lado todo lo demás.

3. Análisis de los puntos de intersección y establecimiento de la secuencia cronológica relativa. Se estudiaron todos los puntos de intersección entre trazados y se establecieron las relaciones de antero-posterioridad según el siguiente criterio básico: por un lado, cuando un trazado mantiene su rectitud al atravesar un punto de intersección, cabe pensar que la aparición de la intersección (es decir la aparición del otro trazado o trazados que allí confluyen) es posterior al de aquel primero que se estaba considerando; por otro lado, a la inversa, un trazado que desemboca en una intersección y no la atraviesa, se entiende que ha surgido con "posterioridad" al trazado con el que interseca. En la medida en que el tejido urbano presenta cientos de confluencias encadenadas, fue posible deducir de ese encadenamiento una secuencia cronológica relativa por fases para la evolución viaria de todo el asentamiento. Cuando estas fases las tuvimos claras confeccionamos lo que hemos denominado "grafos de fase" que representan el desarrollo de la retícula urbana en cada momento sucesivo.

4. Establecimiento de la secuencia cronológica absoluta. En esta etapa de los trabajos se trató de recurrir a toda la información cartográfica y escrita de archivo que pudo servirnos para precisar la datación, no tanto de los trazados, como de los puntos de intersección entre ellos ya que el origen de estos suele estar denotado por la aparición de algún hito o actividad humana concreta asociada a ese punto; la construcción de un puente para cruzar un riachuelo, la erección de una fuente, el surgimiento de una plaza de mercado, etc.

Como resultado de esta investigación en la trama viaria del casco histórico de Vitoria se detectaron siete fases de su evolución (Fig. 6): 1) triángulo genésico (mediados siglo VIII ante quem); 2) inicios como polo tractor (principios del siglo XII ante quem); 3) consolidación como único polo tractor (mediados del siglo XII); 4) ampliación occidental (finales del siglo XII); 5) 


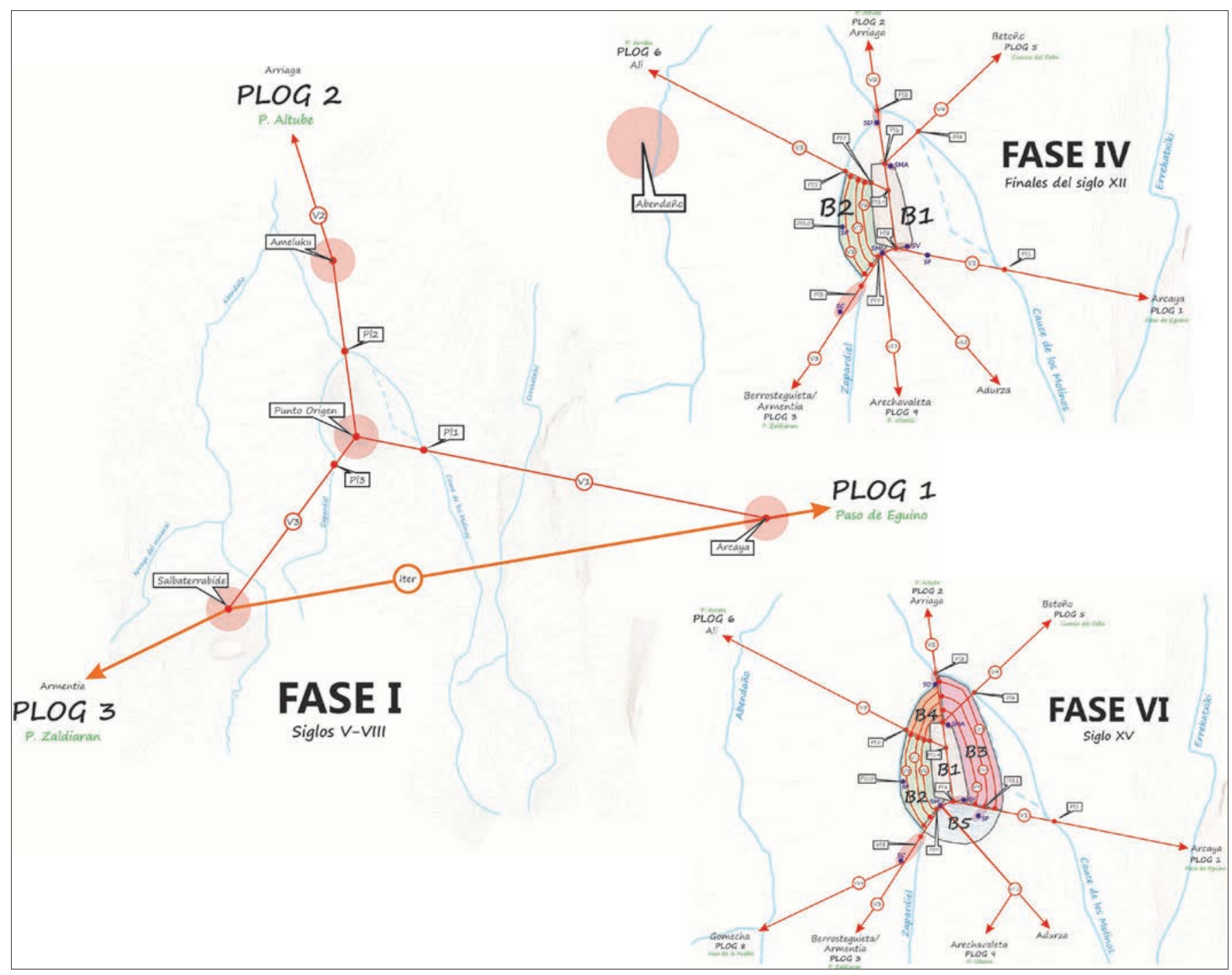

Figura 6. Tres de las fases evolutivas del centro histórico de Vitoria-Gasteiz individualizadas mediante el análisis estratigráfico del trazado viario. Fuente: García-Gómez 2017.

ampliación oriental (segunda mitad del siglo XIII); 6) cierre septentrional (principios del siglo XIV) y 7) cierre meridional (finales del siglo XV).

\subsection{Análisis estratigráfico de paisajes históricos extra-urbanos, del caso de los Montes de Vitoria}

Si la cultura material, artefactual, ocupa un lugar central en el campo de intereses de la Arqueología, también debería ocuparlo la cultura "ecofactual". De hecho, el paisaje en torno a nuestras ciudades que, acaso por comodidad, solemos calificar de natural, tiene muy poco de natural, al menos en un sentido arqueológico, pues es de sobra conocido que también ese es un espacio profundamente transformado por la acción del ser humano a lo largo de los siglos. Así, un árbol trasmocho, es decir, un árbol cuyo crecimiento ha sido conducido de una determinada manera a lo largo de decenios para la producción de madera (da igual si para el carboneo o la construcción) debería ser considerado un artefacto tan arqueológico como una cerámica por más que al tratarse de un ser vivo este haya tendido a recuperar su aspecto natural después de la desaparición de ciertos modos de explotación del bosque.

Partiendo por lo tanto de la idea de que el estudio de los "ecofactos" debería recibir una mayor atención por parte de la Arqueología de la Arquitectura, creímos que probablemente la metodología empleada en el casco histórico de Vitoria-Gasteiz podría ser aplicable en su hinterland paisajístico (García-Gómez et al. 2011 memoria inédita; Martínez Montecelo y Rodríguez Fernández 2013). Escogimos para ello una zona concreta de 
los llamados Montes de Vitoria, un entorno de masa boscosa que ha sido del que tradicionalmente se ha servido la ciudad para obtener todo tipo de recursos forestales. En este caso el procedimiento de "análisis clúster" que aplicamos podría sintetizarse en estos siete pasos:

1. Elaboración de la cartografía base. Al igual que en los trabajos realizados en la Catedral Santa María y el casco histórico de Vitoria, este trabajo hubo de cimentarse sobre la articulación de un Sistema de Información Geográfica. Para ello, aparte de las cuestiones puramente informáticas y de programación se realizó una labor básica de documentación cartográfica (trabajando con varias escalas a la vez, 1:5000, 1:25000 y 1:50000). También se llevó a cabo un vaciado toponímico, bibliográfico e incluso etnográfico que nos permitiera tener un soporte bien articulado sobre el que poder ir volcando todos los datos recopilados durante la prospección.

2. Prospección y elementos. La cobertura de la prospección tuvo un carácter de muestreo, es decir, se limitó a un $30 \%$ del área de estudio. Si bien desde el punto de vista estadístico, lo ideal hubiera sido aplicar un muestreo aleatorio simple, dados los importantes contrastes altitudinales optamos por un muestreo sistemático. El número de prospectores por unidad de muestreo fue de dos, dispuestos a una distancia -condicionada por las características del terreno y la época del año en que se realizaba la prospección- de 20 metros, con lo cual en cada pasada quedaba barrida una franja de unos 40 metros. El sistema de barrido consistió en recorridos de campo que seguían unas curvas de nivel determinadas, en concreto las situadas a una equidistancia de 50 metros, comenzando desde la isohipsa de los 650 metros. Esta equidistancia entre las unidades de muestreo fue determinada en función de las características propias de la cuenca visual. Los elementos objeto de registro fueron antiguos mojones, vestigios de antiguos caminos, árboles trasmochos, jarales, carboneras, abejeras, tejeras, caleros, neveras, canteras, fuentes e indicios de viejas cabañas.

3. Georreferenciación. Cada equipo de prospección disponía de un GPS que le permitía geolocalizar su hallazgo con gran precisión y sobre todo de un modo digital fácilmente descargable e insertable en el Sistema de Información Geográfica.

4. Determinación de las variables diagnóstico. Durante el trabajo de prospección, de cada uno de los elementos registrados se hizo un desglose por variables. En un primer momento, fuimos maximalistas (Sánchez-Zufiaurre 2007: 73) considerando en el registro prácticamente todo tipo de variables de las cuales aún no teníamos la certeza, pero creíamos que iban a ser interesantes. Es por ello que una vez completada la prospección fue necesario trabajar con el Sistema de Información Geográfica para descartar aquellas variables que por ser demasiado comunes $-\mathrm{o}$ todo lo contrario, por ser demasiado excepcionales- no iban a ser muy significativas a la hora de formar las agrupaciones. Al final, de todos los elementos registrados nos quedamos tan solo con cinco variables: "especie de árbol", "datación dendrocronológica del árbol", "tamaño de carbonera", "proporción de la carbonera" y "perfil superficial de carbonera".

5. Individualización de clústeres. De la distinta combinación de dichas variables obtuvimos un total de 29 clústeres que tenían una localización concreta dentro del área de muestreo.

6. Análisis de relaciones estratigráficas y elaboración de la secuencia cronológica relativa. En la medida en que un número considerable de los elementos que componían esos clústeres estaban situados en sus zonas fronterizas, llegando incluso a entrar en contacto, el análisis topológico de estos nos permitió deducir unas relaciones estratigráficas de anteroposterioridad y por lo tanto proponer una secuencia cronológica relativa de la sucesión de ecofactos dentro de la zona de estudio.

7. Establecimiento de la secuencia cronológica absoluta. Aunque, en un intento de facilitar la comprensión de nuestra metodología, hemos mantenido esta etapa del establecimiento de la cronología absoluta en último lugar, en este trabajo, las dataciones dendrocronológicas, realizadas en diversos árboles de la masa forestal de los montes de Vitoria, nos sirvieron tanto de variable para diferenciar clústeres como de referencia cronológica para asignar una datación absoluta.

Como resultado de esta investigación aplicada en los montes de Vitoria se formaron como acabamos de comentar 29 clústeres (Fig. 7), los cuales han sido interpretados como pertenecientes a seis momentos diferentes en la evolución de la explotación de los recursos forestales: 1) un modelo productivo de corte medieval, modelo 1 (segunda mitad del siglo XV); 2) difusión/expansión del modelo 1 (siglo XVI); 3) ocaso del modelo 


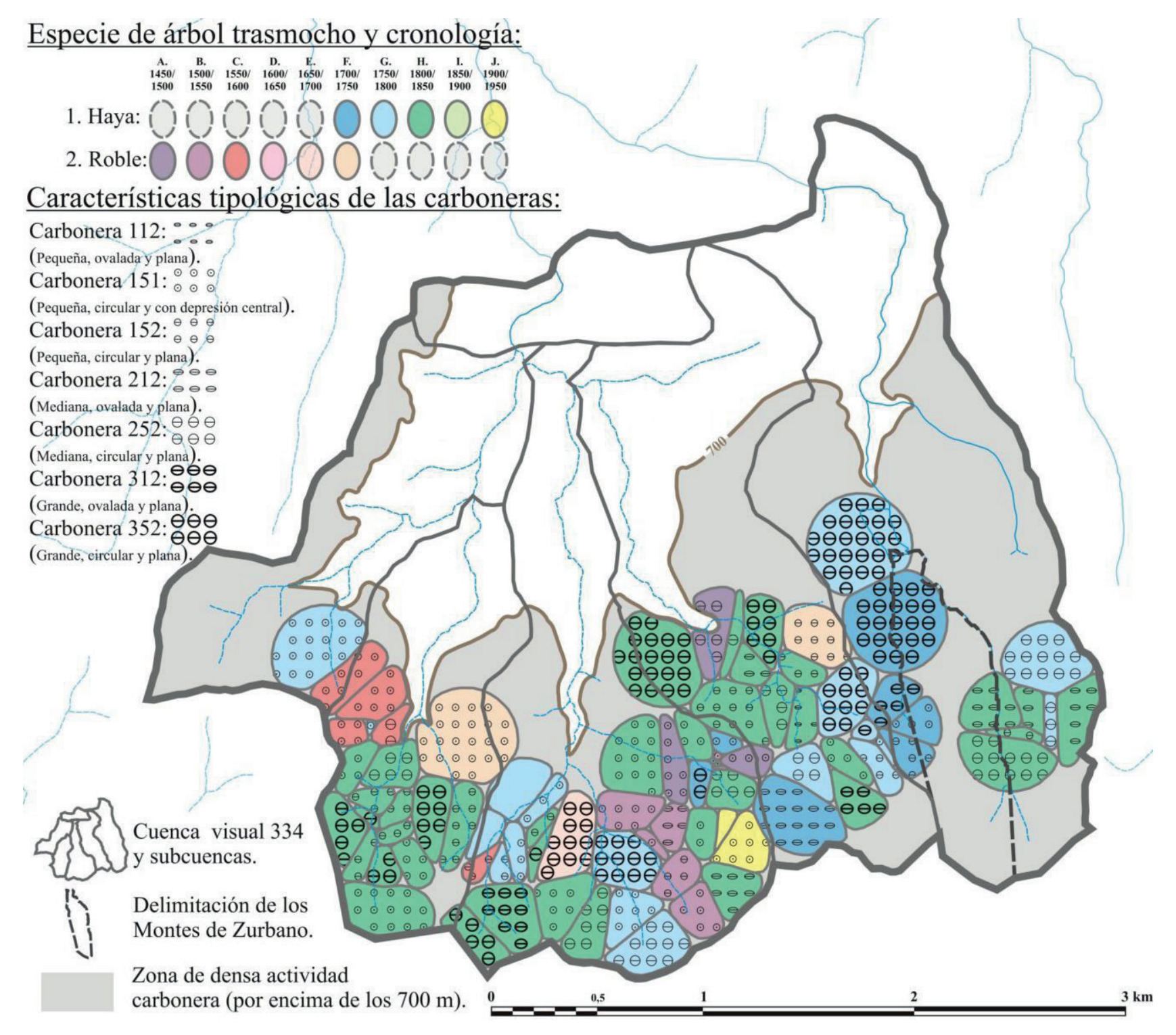

Figura 7. Clústeres individualizados en el estudio de los Montes de Vitoria. Fuentes: García-Gómez et al. 2011 y Martínez Montecelo y Rodríguez Fernández 2013.

1 (siglo XVII); 4) introducción de un nuevo modelo productivo, modelo 2 (siglo XVIII); 5) ocaso del modelo 2 (siglo XIX) y 6) actividad residual (siglo XX).

\section{A MODO DE CONCLUSIÓN}

Como habrá podido observarse, aunque solo de un modo testimonial, al final de la explicación de cada procedimiento metodológico hemos querido dejar constancia de la secuencia interpretativa resultante de su aplicación. Hemos dudado de si hacerlo aportaría algo a este artículo, y la razón de que finalmente hayamos optado por su inclusión responde a que solo de este modo tendríamos el pie para introducir una de las ideas con las que queríamos concluir este trabajo. Esa idea es que todos estos procedimientos analíticos no se pueden autojustificar; el método por el método no nos sirve si no es para "poner voz" a la cultura material, a la estratigrafía, permitiendo que la arqueología haga su aportación genuina desde el lenguaje de las cosas. En cada uno de los proyectos a los que hemos hecho referencia, esas secuencias evolutivas desglosadas por fases que aquí aparecen al final, son solo en realidad el punto de partida de la verdadera investigación porque todas ellas deben ser contrastadas, enriquecidas, corregidas, recurriendo a 
otras fuentes, y deben entrar en el debate historiográfico con especialistas de otras disciplinas. Para aquellos que estén interesados en esa segunda parte de las investigaciones, nos remitimos a todas las referencias bibliográficas aportadas a lo largo de estas líneas.

Para finalizar, muy a propósito apuntábamos en el título de este artículo que esta es "una panorámica metodológica" sobre Arqueología de la Arquitectura, lo cual lleva implícito que por supuesto sabemos que son posibles otras panorámicas igualmente válidas. Han quedado fuera muchos proyectos y muchos nombres importantes dentro de nuestra disciplina, pero sobre todo han quedado fuera muchas cuestiones que van a ser claves para su evolución o supervivencia. No hemos podido profundizar por ejemplo en todo lo relativo a las tecnologías que están revolucionando nuestra forma de percibir el fenómeno construido. Apenas hemos hablado de las últimas técnicas de registro topográfico, de la fotogrametría convergente, del láser-escáner, del GPS. Tampoco de las modernas herramientas cartográficas, desde los Sistemas de Información Geográfica al propio Google Earth, ni de las Infraestructuras de Datos Espaciales (IDE). Tampoco hemos podido dar cabida al reto que supone la gran capacidad de procesamiento de datos que nos ofrecen en la actualidad las herramientas informáticas, y que creemos no están siendo suficientemente aprovechadas por la Arqueología de la Arquitectura, nos referimos a cuestiones como el data mining o la automatización del trabajo de lectura estratigráfica de alzados (Azkarate et al. 2018; Mesanza-Moraza 2017; Mesanza et al. e. p.). Todas estas cuestiones son clave, porque, desde el momento en que todas ellas influyen e influirán en nuestra forma de percibir el objeto de estudio (la arquitectura, lo construido, el paisaje antropizado, etc.), influirán también en la definición futura de nuestra disciplina.

\section{AGRADECIMIENTOS}

Trabajo realizado en el marco del Proyecto de investigación "La Arqueología de la Arquitectura: nuevos retos metodológicos y su aplicación en Europa y América Latina" (HAR2015-64439-P), financiado por el Ministerio de Economía y Competitividad y Fondo Europeo de Desarrollo Regional (FEDER), así como bajo el proyecto "Arqueología de la Arquitectura entre el viejo y el nuevo mundo: de la estratigrafía del edificio a la estratigrafía de la trama urbana" (PID2019-109464GB-I00), financiado por el Ministerio de Ciencia, Innovación y Universidades.
Asimismo, parte de los proyectos que aquí aparecen se han podido llevar a cabo gracias al apoyo y financiación del Grupo de Investigación en Patrimonio Construido de la UPV/EHU en colaboración con la empresa Enklabe Koop. S. Txikia.

\section{MEMORIAS CIENTÍFICAS INÉDITAS CONSULTADAS}

Azkarate Garai-Olaun, A. 2010: Estudio histórico-arqueológico del casco histórico de Vitoria-Gasteiz. Protocolos de intervención, modelos de gestión y Sistema de Información Patrimonial (SWIP). (Memoria inédita). García-Gómez, I., Domínguez Beltrán de Heredia, I. C., Fernández de Gorostiza López de Viñaspre, M., Gómez Calvo, E., Martínez Montecelo, A., Rodríguez Fernández, J. y Azkarate Garai-Olaun, A. 2011: Montes de Vitoria: Análisis clúster aplicado al estudio estratigráfico de paisajes antropizados. Grupo de Investigación en Patrimonio Construido (GPAC) de la Universidad del País Vasco (UPV/EHU). Vitoria-Gasteiz. (Memoria inédita).

Mesanza-Moraza, A. 2017: Análisis multivariante aplicado a la lectura estratigráfica de alzados. Universidad de Salamanca (Tesis doctoral inédita).

\section{BIBLIOGRAFÍA}

Álvarez González, I., Lopetegi Galarraga, A., Mesanza Moraza, A., Valle Melón, J. M. y Vicente Espina, I. 2003: "Diferentes propuestas para la representación geométrica de edificios históricos", Arqueología de la Arquitectura, 2, pp. 9-12. https://doi.org/10.3989/arq.arqt.2003.18

Azkarate, A. 2001: Arqueología de la Arquitectura (Experiencias de investigación desde la Universidad del País Vasco). Lección inaugural de apertura del Curso Académico de la Universidad del País Vasco/Euskal Herriko Unibertsitatea, 2001-2002. Universidad del País Vasco, Bilbao.

Azkarate, A. 2010: "El análisis estratigráfico en la restauración del patrimonio construido", en Arqueología aplicada al estudio de edificios históricos. Últimas tendencias metodológicas, pp. 51-54. Ministerio de Cultura, Madrid.

Azkarate, A., Camara, J. I., Lasagabaster, J. I. y Latorre, P. 2001: Plan Director para la Restauración de la Catedral de Santa María de VitoriaGasteiz. Vitoria-Gasteiz. Diputación Foral de Álava, Vitoria-Gasteiz.

Azkarate Garai-Olaun, A., Caballero Zoreda, L. y Quirós Castillo, J. A. 2002: "Arqueología de la Arquitectura: definición disciplinar y nuevas perspectivas", Arqueología de la Arquitectura, 1, pp. 7-10.

Azkarate Garai-Olaun, A., García-Gómez, I. y Mesanza-Moraza, A. 2018: "Análisis clúster: un primer paso sobre técnicas cuantitativas en Arqueología de la Arquitectura", Arqueología de la Arquitectura, 15, pp. 1-18. https://doi.org/10.3989/arq.arqt.2018.014

Bermejo, J. 2009: "Leyendo los espacios: una aproximación crítica a la síntesis espacial como herramienta de análisis arqueológico", Arqueología de la Arquitectura, 6, pp. 47-62. https://doi.org/10.3989/arqarqt.2009.09004

Brogiolo, G. P. 1988: Archeologia dell'edilizia storica. Edizioni New Press, Como. Caballero Zoreda, L. 1995: "Método para el análisis estratigráfico de construcciones históricas o lectura de paramentos", Informes de la Construcción, 46, 435, pp. 37-46. https://doi.org/10.3989/ic.1995.v46.i435.1096

Camporeale, S., Gabrielli, F., Pais, A. y Parenti, R. 2001: "La facciata del Palazzo Pubblico di Siena. Stratigrafia e fonti documentali”, Archeologia dell'Architettura, VI, pp. 63-100.

Chevallier, R. 1997: Les voies romaines. Picard, Paris.

Ferrando Carona, I., Mannoni, T. y Pagella, R. 1989: "Cronotipologia”, Archeologia Medievale, XVI, pp. 647-661.

Gabbrielli, F. 1996: "La cronotipología relativa come metodo di analisi degli elevati: la facciata del Palazzo Pubblico di Siena", Archeologia dell'Architettura, I, pp. 17-40. 
Gabbrielli, F. 1998: "La Chiesa dell'abbazia di S. Galgano. I. Stereotomia degli archi e fasi construttive", Archeologia dell'Architettura, III, pp. 15-44.

García-Gómez, I. 2017: Vitoria-Gasteiz y su hinterland. Evolución de un sistema urbano entre los siglos XI y XV. Colección Patrimonio, Territorio y Paisaje. Servicio editorial de la Universidad del País Vasco/Euskal Herriko Unibertsitatea, Vitoria-Gasteiz.

García-Gómez, I. 2019: “Arqueología de la Arquitectura. Nociones básicas y perspectivas de futuro", Atempo, 2, pp.120-135.

García-Gómez, I., Fernández de Gorostiza López de Viñaspre, M. y Mesanza Moraza, A. 2011: "Láser escáner y nubes de puntos. Un horizonte aplicado al análisis arqueológico de edificios”, Arqueología de la Arquitectura, 8, pp. 25-44. https://doi.org/10.3989/arqarqt.2011.10019

Harris, E. C. 1979: Principles of archaeological stratigraphy. Academic Press, Londres.

Harris, E. C. 1991: Principios de estratigrafia arqueológica. Crítica, Barcelona. Hillier, B. y Hanson, J. 1989. The social logic of space. Cambrigdge University Press, Cambrigdge.

Mannoni, T. 1998: "Analisi archeologiche degli edifici con strutture portanti non visibili”, Archeologia dell' Architettura, III, pp. 81-85.

Martín Talaverano, R. 2014: "Documentación gráfica de edificios históricos: principios, aplicaciones y perspectivas", Arqueología de la Arquitectura, 11, pp. 1-26. https://doi.org/10.3989/arq.arqt.2014.014
Martínez Montecelo, A. y Rodríguez Fernández, J. 2013: “Documentación sistemática del arbolado trasmocho. Un caso práctico en los montes altos de Vitoria", Cuadernos de la Sociedad Española de Ciencias Forestales, 38, pp. 149-158. https://doi.org/10.31167/csef.v0i38.10310

Mesanza-Moraza, A., García-Gómez, I. y Azkarate, A. (en prensa). "Machine learning for the built heritage archaeological study", Journal on Computing and Cultural Heritage.

Plata, A. 2008: Génesis de una Villa Medieval. Arqueología, Paisaje y Arquitectura del Valle Salado de Añana (Álava). Servicio Central de Publicaciones del Gobierno Vasco, Vitoria-Gasteiz.

Plata, A. y Erkiaga, A. 2018: El sistema de producción de sal de Añana: Valle Salado (Araba-Álava. País Vasco). Colección Patrimonio, Territorio y Paisaje. Vol. 3. Servicio editorial de la Universidad del País Vasco/ Euskal Herriko Unibertsitatea, Vitoria-Gasteiz.

Sánchez-Zufiaurre, L. 2007: Técnicas constructivas medievales. Nuevos documentos arqueológicos para el estudio de la Alta Edad Media en Álava. Servicio Central de Publicaciones del Gobierno Vasco, VitoriaGasteiz.

Utrero Agudo, M. A. 2010: “Archaeology. Archeologia. Arqueología. Hacia el análisis de la Arquitectura", en Arqueología aplicada al estudio e interpretación de edificios históricos. Últimas tendencias metodológicas, pp. 11-23. Ministerio de Cultura, Madrid. 